Caligrama, Belo Horizonte, v. 23, n. 3, p. 47-62, 2018

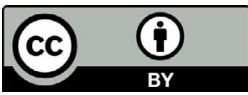

\title{
Colonias sin metrópolis: neoimperialismo y barbarie en Gracias de Pablo Katchadjian
}

\section{Colonies Without Metropole: Neoimperialism and Barbarism in Gracias by Pablo Katchadjian}

\author{
Adolfo R. Posada \\ Universitatea de Vest din Timisoara, Timisoara / Romênia \\ adolfo.rodriguez.posada@gmail.com
}

Resumen: La novela Gracias del escritor argentino Pablo Katchadjian, publicada en 2011, se construye sobre los principales fundamentos de la teoría poscolonial: la descolonización como proceso violento de emancipación por parte de los oprimidos frente a la explotación y la tiranía; los actos inhumanos, fruto de la barbarie imperialista, cometidos contra la dignidad del hombre; la construcción y reivindicación de la identidad de los sujetos colonizados a partir del indigenismo y el criollismo. No obstante, la novela de Katchadjian apunta más allá de los presupuestos destacados que han identificado el poscolonialismo como corriente de pensamiento durante el siglo pasado, para hacerse eco de los conflictos generados por el desarrollo de un nuevo imperialismo, transnacional y neoliberal, ligado a la explotación de los recursos por parte de las corporaciones multinacionales y a merced de la deslocalización capitalista según el paulatino proceso de globalización del mundo en el cambio de siglo. Así pues, a la luz de los planteamientos aquí resumidos y recogidos por los trabajos de Frantz Fanon (1988), Stuart Hall (1996), Miguel Mellino (2008), Étienne Balibar (2017) o Emanuela Fornari (2017), entre otros, analizaremos los rasgos poscoloniales de la obra narrativa de Katchadjian en el marco de los avatares de la globalización, a fin de ejemplificar, a través de la lucha violenta y la emancipación del sujeto colonizado representadas en Gracias, cómo el antiguo espíritu imperialista sigue operando, como ha señalado Eduardo Grüner (2002), en la actual era del neocolonialismo capitalista y la globalización multinacional.

Palabras clave: poscolonialismo; globalización; neoimperialismo; literatura del siglo XXI; Katchadjian. 


\begin{abstract}
The novel Gracias by the Argentine writer Pablo Katchadjian, published in 2011 , is built on the main foundations of postcolonial theory: decolonization as a violent process of emancipation by the oppressed against exploitation and tyranny; the inhuman acts, fruit of imperialist barbarism, taken against the human being dignity; the construction and vindication of the colonized subjects' identity through the indigenism and criollismo. However, Katchadjian's novel goes beyond the outstanding assumptions that have identified postcolonialism as critical thought during the last century to evince the conflicts generated by the development of a new imperialism, transnational and neoliberal, linked to the exploitation of resources by multinational corporations and the capitalist relocation due to the gradual process of worldwide globalization at the turn of the century. Therefore, in light of these approaches - collected as well by the works of Frantz Fanon (1988), Étienne Balibar (2017), Stuart Hall, Miguel Mellino (2008) or Emanuela Fornari (2017), among others - this article analyses the postcolonial features of Katchadjian's narrative work in the context of the globalization issues. Taking into account the emancipation and the violent struggle led by the colonized subjects represented in Gracias, the final aim is to exemplify how the old imperialist spirit continues to operate, as Eduardo Grüner (2002) has pointed out, in the current era of capitalist neocolonialism and the multinational globalization.
\end{abstract}

Keywords: postcolonialism; globalization; neoimperialism; 21st century literature; Katchadjian.

Bajo el inocente proceso de globalización y mundialización de las economías y los sistemas de producción neoliberales se ocultan nuevas formas de dominación imperialista. Se trata de la imposición de diferentes vías de colonialismo, «más allá de los “imperios"» como sostiene Étienne Balibar (2017), fomentadas ya no por las grandes potencias nacionales en su deseo imparable de expansión, sino por las grandes corporaciones multinacionales y las élites financieras que las avalan. ${ }^{1}$

\footnotetext{
${ }^{1}$ Estas formas de sumisión, dominación y expansión neoimperialistas son intrínsecas al que, desde Fredric Jameson, se viene denominando «capitalismo tardío», un modelo de sociedad posindustrial y posfordista que ha asentado las bases de «una nueva división internacional del trabajo, fruto de una vertiginosa transnacionalización de la economía, favorecida por las innovaciones tecnológicas en el campo de la comunicación, del transporte y de los medios masivos de comunicación, cuyo notable desarrollo ha incrementado decididamente la velocidad y la capacidad de extensión planetaria de la circulación de mercancías, noticias, imágenes, fuerza de trabajo y capitales» (MELLINO, 2008, p. 89).
} 
Esta percepción crítica del nuevo mundo globalizado corre el peligro de ser tachada siempre de psicótica y conspiranoica. Nada más lejos de la realidad. Vivimos tiempos en que el espíritu crítico, por culpa o gracias -según se mire- a la era de la información, se ha convertido en un enemigo para los intereses neocoloniales de las grandes potencias/ corporaciones. Todo discurso que ponga en jaque la versión oficial difundida por los Estados dominantes es tachado de desinformación o fake news. Pero, más allá de la difusión malintencionada de informaciones falsas y teorías conspiranoicas peregrinas, la realidad es que ciertas actitudes y dinámicas intrínsecas a la globalización, guste o no, son síntoma de la «persistencia de la condición colonial en el mundo global contemporáneo» (MELLINO, 2008, p. 15).

Día tras día observamos con inquietud cómo la censura trata de imponerse al libre pensamiento y al juicio crítico. Porque el imperialismo nunca se vio derrotado pese a los procesos de descolonización del siglo XX; únicamente se camufló en nuevas formas de dominación mucho más sutiles y avanzadas, «formas de dominación todas ellas», como denuncia Eduardo Grüner (2002, p. 177) en El fin de las pequeñas historias, «que típicamente echan raíces en la historia del colonialismo europeo moderno y que continúan operando en la actual era de neo/poscolonialismo y globalización».

La posibilidad de prolongar el espectro del colonialismo decimonónico a la deriva neoimperialista de ciertas prácticas corporativas vinculadas a la expansión multinacional fomenta, según Mellino (2008, p. 42), «un diálogo fecundo entre la crítica poscolonial y los movimientos antiglobalización en todo el mundo». En este sentido la crítica poscolonial se muestra más activa y fecunda que nunca, por cuanto lo poscolonial no sólo «deviene una metáfora de la condición posmoderna» (MELLINO, 2008, p. 51), sino asimismo del mundo globalizado y por tanto de nuestro presente.

Siguiendo a Arif Dirlik, esgrime Mellino (2008, p. 95) que en el contexto de la geopolítica mundial «los modos de comprensión estrechamente ligados a los conceptos de Tercer Mundo y de Estadonación», que han sido los pilares de la crítica poscolonial en su primer estadio, «se vuelven obsoletos y anacrónicos ante las dinámicas de desterritorialización, flexibilización y descentramiento del capitalismo tardío»». Opinión compartida por Appadurai (2001, p. 46), quien sostiene que el mundo globalizado «ya no puede ser captado en los términos 
de los modelos basados en el binomio centro-periferia (ni siquiera por aquellos modelos que hablan de muchos centros y muchas periferias)». Por su parte, Stuart Hall (1996, ${ }^{2}$ p. 301 apud MELLINO, 2008, p. 23) ha defendido que la crítica poscolonial nos ayuda a identificar «las nuevas relaciones y disposiciones de poder que están emergiendo en la coyuntura del presente». Si algo nos ha enseñado el poscolonialismo como corriente de pensamiento, según argumenta Balibar (2017) teniendo en cuenta «las nuevas condiciones que la "mundialización" le impone», es a desconfiar de las apariencias y los buenos deseos que parecen impulsar lemas progresistas como la globalización y el avance tecnológico defendidos por el llamado «imperio del "neoliberalismo"» (BALIBAR, 2017).

Con el subterfugio de la prosperidad económica y el progreso tecnológico, ${ }^{3}$ la realidad es que se está imponiendo un régimen neoliberal totalitario - minarquista a fin de cuentas $-^{-4}$ en todo el planeta, mediante una serie de medidas que, si bien parecen abogar por la seguridad de la ciudadanía -los llamados "bombardeos humanitarios" son un ejemplo extremo-, su objetivo último, tal y como se ha demostrado a juzgar por los hechos más allá de las versiones oficiales, es la expansión neocolonialista. ${ }^{5}$ Es la lectura que algunas voces críticas realizan de

${ }^{2}$ HALL, S. When Was the Post-Colonial? Thinking at the Limit. In: CHAMBERS, I.; CURTI, L. (Ed.). The Post-Colonial Question: Common Skies, Divided Horizons. Londres: Routledge, 1996. p. 242-260.

${ }^{3}$ Según Appadurai (2001), el proceso de globalización económica y de expansión tecnológica, pese a la canibalización entre la identidad y la diferencia cultural que supone la consagración de una cultura homogénea mundial, presenta una cara amable: «Lo positivo está en la expansión de muchos horizontes de esperanza y fantasía para los individuos; en la difusión global de la terapia de rehidratación por vía oral y otros instrumentos de baja tecnología que atañen al bienestar y a la calidad de vida» (APPADURAI, 2001, p. 56).

${ }^{4}$ El minarquismo es un modelo político-económico vinculado al pensamiento libertario y a la teoría anarcocapitalista. El término fue difundido por Samuel Konkin, partidario de la reducción de los Estados a sus mínimas funciones.

${ }^{5}$ La razón de ser de la incesante expansión económica promovida por los poderos financieros, según Fornari (2017), se debe a que «la acumulación capitalista avanza a través de un movimiento continuo de apropiación y reconfiguración de espacios antes externos y extraños a la lógica del capital, manifestando la necesidad de tener siempre algo "externo a él" para poder garantizar su propia estabilización». Se trata de expandir el capitalismo por todo el globo, incluso a aquellos espacios de resistencia, para que 
la Guerra de Siria, conflicto que es reflejo de la lucha geopolítica que mantienen los viejos y nuevos imperios. En palabras de Hall (1996, p. 303-304 apud MELLINO, 2008, p. 31), «lo "colonial” no ha muerto, desde el momento en que continúa viviendo en sus secuelas».

Tal es la lectura que parece ofrecer Gracias del escritor argentino Pablo Katchadjian, publicada en 2011. Ambientada en una isla remota donde se localiza una colonia, narra la historia de un grupo de esclavos, los cuales, violentados por los actos de barbarie cometidos por el tirano Aníbal, acaban por alzarse en una revolución. Gracias al efecto alucinógeno provocado por unas extrañas raíces que crecen en la isla, el protagonista aúna la fuerza suficiente para asesinar a Aníbal y proceder a la liberación de los esclavos en compañía de Hugo y Nínive, con la consiguiente muerte de los amos y las conquistas de sus castillos. Sin embargo, uno de los esclavos liberados a las órdenes de Hugo, Calambra, se hacina en un castillo con una serie de revolucionarios para convertirse en el nuevo tirano de la colonia, llegando a cometer peores actos de barbarie que los sufridos con anterioridad por los personajes. La historia finaliza con una extraña podredumbre de cenizas y gusanos asolando y contaminando por entero la isla, provocando su total desalojo, de la que el protagonista consigue escapar embarcado en el penúltimo de los barcos.

Si por algo destaca la novela de Katchadjian es por cuanto su trama se construye sobre los principales fundamentos de la teoría poscolonial: la descolonización como proceso violento de emancipación por parte de los oprimidos frente a la explotación y la tiranía; los actos inhumanos, fruto de la barbarie imperialista, cometidos contra la dignidad del hombre; o la construcción y reivindicación de la identidad de los sujetos colonizados a partir de símbolos del indigenismo -véase la simbología que rodea al poder alucinógeno de las raíces en Gracias.

la sociedad planetaria en su totalidad adopte la forma de vida occidental basada en el consumo, aunque ello signifique abrir frentes y provocar guerras (neo)coloniales; aunque suponga cosificar y alienar al ser humano hasta sus últimas consecuencias mediante la esclavitud de la acumulación del capital y el deseo extremo de consumo de mercancías y productos, ya sean objetos (moda, tecnología, lujo), ya sean experiencias (viajes, parques de atracciones, festivales de música, espectáculos, deportes). De hecho, el modelo económico capitalista se basa fundamentalmente en generar artificialmente una demanda de consumo a priori inexistente en virtud del lanzamiento de un producto o servicio novedoso, o bien por la explotación de una tecnología disruptiva. 
Sin embargo, he aquí lo interesante, la novela apunta más allá de los presupuestos destacados que han identificado el poscolonialismo como corriente crítica, para hacerse eco de los conflictos generados por el desarrollo de un nuevo imperialismo y colonialismo económico, así como las nuevas formas de esclavitud ligadas a estos, en el siglo XXI. Como recuerda Slavoj Žižek ${ }^{6}$, el Capital es la máquina global anónima de colonización y esclavitud de la humanidad, como así se ha ocurrido en numerosos países de América Latina en las últimas décadas. ${ }^{7}$

Gracias de Katchadjian retoma las trazas reconocibles de la teoría poscolonial para trascender su propio campo, es decir, los discursos teóricos en torno al empoderamiento de los grupos excluidos y la dialéctica entre la explotación de la metrópolis europea y la opresión sufrida por las naciones colonizadas, desplazándola a un sentido amplio de la lucha de clases, más allá de fronteras y grupos sociales, y lejos ya de unas coordenadas geográficas concretas, las cuales están siendo difuminadas por el proceso globalizador y deslocalizador que impulsa la expansión capitalista.

Si la crítica poscolonial anhelaba la construcción de una historia que no ignorase al sujeto subalterno y los grupos excluidos -anhelo que en cierto modo se ha o se está logrando-, un nuevo desafío surge para la crítica poscolonial: reconfigurar un discurso crítico y de resistencia más allá de la razón colonial del imperialismo de los pasados siglos frente a las nuevas formas de dominación en la era de la globalización. Como sostiene Miguel Mellino (2008, p. 42), en el nuevo siglo se ha producido «un diálogo fecundo entre la crítica poscolonial y los movimientos antiglobalización en todo el mundo». ${ }^{8}$ Y así se vislumbra en la perspectiva

\footnotetext{
${ }^{6}$ «El verdadero horror no está en el contenido particular que se esconde tras la universalidad del capital global, sino en el hecho de que el capital efectivamente es una máquina global anónima que sigue su curso ciegamente, sin ningún agente secreto que lo anime» (ŽIŽEK, 1998, p. 46).

${ }^{7}$ Así mismo acontece en la novela de Katchadjian, pues en ella justamente el poder, como puntualiza Žižek (1998), es anónimo.

${ }^{8}$ A la luz de las reflexiones de Linda Hutcheon, argumenta Mellino (2008, p. 112) que puede interpretarse la posmodernidad filosófica y artística como «un pensamiento crítico frente a las estructuras ideológicas, políticas y económicas dominantes de la sociedad contemporánea». Esta premisa es extensible y se amplía como elemento nuclear en la literatura de la globalización, en cuyo contexto la emancipación frente al poder imperial traspasa el horizonte del campo de batalla de las antiguas colonias para trasladarse al ámbito urbano de las megalópolis del siglo XXI y su resistencia
} 
que la crítica poscolonial ha adoptado a través de las reflexiones de Beck (1998), Appadurai (2001), Mignolo (2003) o Sassen (2007), por citar sólo algunos ejemplos, en torno a la globalización y el nuevo cosmopolitismo.

Dadas las circunstancias, no es de extrañar que numerosas novelas de la literatura española e hispanoamericana, publicadas en los últimos años, presenten argumentos en los que las luchas sociales y las guerras de resistencia al poder neocolonial, el imperialismo capitalista y las nuevas formas de dominación y barbarie del siglo XXI se tornen en protagonistas. Es el caso de Providence (2009) de Juan Francisco Ferré, novela en la cual el espacio urbano de la ciudad norteamericana termina convertido en el escenario geoestratégico de un conflicto armado. Y no es ni mucho menos una excepción, pues novelas recientes como Prólogo para una guerra (2017) de Iván Repila o la última novela de Agustín Fernández Mallo, Trilogía de la guerra (2018), parecen apuntalar esta visión combativa de la actual realidad política y social de nuestro siglo.

En líneas generales, la literatura de la era de la globalización, en la que se enmarcan novelas combativas y antisistema como las de Ferré, Repila y desde luego Gracias de Katchadjian, plantea en su vertiente política una reflexión en clave metafórica "acerca de las crecientes desigualdades que caracterizan al actual orden económico mundial" (MELLINO, 2008, p. 172). Estas desigualdades no responden ya a una mera dialéctica racial y étnica, como sucedía en la etapa colonial, sino a los problemas intrínsecos a un nuevo cosmopolitismo poscolonial y multinacional.

Precisamente esta problemática ligada a la forma en que el viejo colonialismo imperial persiste en el seno de la sociedad global parece ser el referente último y velado de la novela de Katchadjian. No sorprende pues que el mundo ficcional de Gracias se construya en torno a la barbarie de la esclavitud; ni que la novela, leída en el contexto actual en el que se inscribe, parezca remitir su crítica, en última instancia, a un colonialismo corporativo, un colonialismo débil podríamos alegar, vinculado a la deriva imperialista de la cultura económica de la globalización, la expansión del neoliberalismo y el nuevo cosmopolitismo. ${ }^{9}$

ante la alienación, cosificación y nueva esclavitud de la expansión incontrolada del neoliberalismo corporativo y global.

${ }^{9}$ Así caracteriza Mellino (2008, p. 181) el nuevo cosmopolitismo que ha emergido de la progresiva globalización de la política y la economía: «Los cosmopolitas de hoy son frecuentemente víctimas de la modernidad, del despliegue de la lógica totalitaria 
«Tratar los fenómenos relativos al colonialismo como algo ya ocurrido o de igual modo como perteneciente al pasado», alega Mellino (2008, p. 28), «impide afrontar cuestiones espinosas como el neocolonialismo y el Neoimperialismo». Este mismo pensamiento bien puede inspirar a Katchadjian la escritura de una novela acerca de la esclavitud, la explotación y el holocausto en un mundo poscolonial. En consecuencia, no aborda el escritor argentino el colonialismo como un proceso histórico ya pasado, sino como una dinámica histórica del mundo del presente, para denunciar que «los desequilibrios de poder característicos del mundo colonial persisten aún hoy» (MELLINO, 2008, p. 28).

Temas como la explotación de los trabajadores en el Tercer Mundo por parte de las grandes multinacionales y la aparente inmunidad frente a las instituciones que protegen los derechos humanos bien podrían ser los argumentos que dan vida a la metáfora (pos)colonial que encierra Gracias. Ya en los primeros compases de la novela el protagonista reconoce sentirse «el esclavo más esclavo del mundo» (KATCHADJIAN, 2011, p. 25). Desde entonces, el universo ficcional de la novela y sus motivos giran alrededor de la esclavitud, reiterando el sufrimiento y la obsesión del protagonista, representada por el recurrente olor a pescado podrido y muerte del que es incapaz de desprenderse por ser «el olor de la humillación y la esclavitud» (KATCHADJIAN, 2011, p. 13).

El espíritu de la esclavitud indefinida y suspendida en el tiempo instiga la recurrente presencia de la violencia en la novela de Katchadjian. La humanidad que representa se encuentra despojada justamente de toda humanidad. La cosificación absoluta del ser humano llega a tal grado en Gracias que los personajes, tal y como ocurría en la barbarie colonial, son vendidos como meras mercancías, como meros objetos que son remplazados cuando dejan de ser útiles, esto es, cuando su vida se agota.

Todo ello da lugar a la constitución de una antiutopía sobre los rasgos característicos de la propia literatura utópica. Es decir, se trata de una novela que, teniendo por escenario una isla utópica, dista mucho de albergar una sociedad ideal. Justo lo contrario: Katchadjian construye en

del Estado-nación, lo que equivale a decir sujetos y culturas subalternos, olvidados por la movilidad del capitalismo y despojados de los privilegios, del confort y de los automatismos tranquilizadores de la pertenencia nacional. Los símbolos de la comunidad cosmopolita de hoy son por eso los refugiados, los prófugos, la gente de las diásporas, los migrantes, los exiliados, los expatriados». 
su novela un universo posthumano de dolor, en el que no hay cabida para la dignidad del hombre, donde todos los ideales utópicos que han servido como motor para el progreso de la humanidad fracasan estrepitosamente al enfrentarse a una comunidad regida por el totalitarismo, la explotación, la esclavitud absoluta al trabajo y que acaba por forzar la emancipación y empoderamiento de los oprimidos.

Esta visión apocalíptica del mundo poscolonial, posnacional si cabe, reducido esta vez a la tiranía de un nuevo imperialismo, anónimo, deslocalizado y atemporal, permite entender mejor la significación de Gracias. La novela poscolonial, según el planteamiento de Katchadjian, ya no habla de la nación, sino de la esclavitud, la explotación, la barbarie, la violencia y la deshumanización en términos globales y universales. El autor argentino traza a partir de los grandes tópicos identitarios mestizaje y criollismo, raza, etnia, género-y los conflictos que vertebran la literatura poscolonial hispanoamericana desde Rómulo Gallegos hasta Rulfo -barbarie colonial, emancipación subalterna, realismo mágico, criollismo de los personajes, etc.--, un discurso combativo frente a «los efectos perversos del capitalismo global contemporáneo», en palabras de Mellino (2008, p. 143).

En la novela de Katchadjian se observa esta pugna contra la explotación en términos universales y por tanto globales, por ejemplo, en la rebeldía de los personajes subalternos frente al poder dominante gracias a la propia naturaleza. Tomando partido el autor de los elementos clásicos de la novela (pos)colonial latinoamericana, enmarcados en el realismo mágico característico, la tierra misma se convierte en un elemento liberalizador, al brindar a los personajes esclavizados las raíces que permiten abrir su mente y dotarlos de la fuerza para librarse de las cadenas de la tiranía, la opresión y la barbarie. Tanto la tierra como sus raíces son justamente las raíces de la identidad del sujeto subalterno. ${ }^{10}$ Son los instrumentos predilectos de descolonización de los personajes

\footnotetext{
${ }^{10}$ Es en la conversación del protagonista con Calambra donde se revela el sentido metafórico y metonímico de las raíces para los personajes esclavizados como representación de las raíces de tierra, la nación, la fuerza de la liberación frente al tiránico dominio del Imperio: «"Esas no son raíces”, le dije. Él las agarró, las miró con atención, y me dijo que era cierto, que no eran raíces» (KATCHADJIAN, 2011, p. 88-89). Las raíces son las que entrega la fuerza a los hombres, pues como dice Calambra: «ellos piensan que ganaron por las raíces, y que sin raíces no tenemos chances» (KATCHADJIAN, 2011, p. 89).
} 
de Gracias, los que los impulsan y los dotan de la fuerza necesaria para resarcirse de la violencia mediante la propia violencia.

De hecho, sin sacar las cosas de quicio, es posible afirmar que Gracias tiende puentes con la pugna anti-imperialista de Frantz Fanon (1988, p. 73), quien no dudó en afirmar en Los condenados de la tierra que «el hombre colonizado se libera en y por la violencia». Es de notar que el discurso de Fanon (1988), visto desde la óptica actual, es políticamente incorrecto. Así formulado corre el peligro de ser censurado por las leyes mordazas actuales. En especial si se desplaza la idea de fondo de Fanon (1988) a los actuales métodos de explotación en el tercer mundo y las precarias condiciones laborales que se están imponiendo en el resto del planeta por la expansión de un neoliberalismo imparable que antepone el capital a los derechos humanos.

El fin justifica los medios: tal es la lógica del polémico lema combativo de Fanon (1988). Y esta misma lógica, la justificación de la violencia para combatir una violencia mayor, para liberar al ser humano de su tiranía, merced al uso necesario de la fuerza ante la perpetua agresión del impulso imperialista de los dominantes, en buena medida condiciona la presencia de la violencia como reacción inevitable frente a los actos de barbarie representados en la novela de Katchadjian. Pues la historia de liberación contenida en Gracias es expresión precisamente de un fin noble: la resistencia a las nuevas formas emergentes de dominación, explotación y deshumanización en el siglo XXI.

Resulta revelador en este sentido que el protagonista de Gracias llegue a la isla en una «jaula de madera junto con los otros doscientos esclavos» (KATCHADJIAN, 2011, p. 5). Katchadjian presenta así mismo y desde un primer momento a los personajes cosificados y animalizados, como si la humanidad estuviera destinada a la jaula de hierro de una u otra forma según el funesto augurio de Max Weber (apud MELLINO, 2008, p. 100), y constantemente se perpetrasen nuevas formas de holocausto y barbarie, como las cruelmente representadas en Gracias.

Tampoco es casual que los personajes respondan a estereotipos universales de la literatura poscolonial y no a personajes específicos que reflejan la idiosincrasia local latinoamericana. El tirano de la novela, «Aníbal, ese monstruo esclavizador y sádico» (KATCHADJIAN, 2011, 24), encarna los horrores y la barbarie de la explotación y la esclavitud colonial. Traficante de personas, es el encargado de someter a los esclavos y convertirlos en meras mercancías de tránsito, explotándolos hasta su desfallecimiento sin dignidad alguna. 
De ahí también que Katchadjian no ofrezca coordenadas geográficas concretas ni sitúe, como se ha adelantado, la acción en unas fronteras específicas dentro del espacio latinoamericano. ${ }^{11}$ Así pues, no se ofrecen en Gracias coordenadas ni signos reveladores para localizar la isla y el puerto de desembarco donde transcurren los acontecimientos narrados en la novela. El paraje únicamente le resulta al protagonista «desconocido y a la vez familiar» (KATCHADJIAN, 2011, p. 5). Se trata de un escenario, por lo tanto, deslocalizado cuyos límites quizás se hayan desdibujado deliberadamente para constatar la propia capacidad del (neo)imperialismo de traspasar las fronteras. ${ }^{12}$ Por la omnipresencia que siempre caracteriza el dominio humano sobre el otro, la isla se convierte en un espacio de colonización global, que no es descabellado interpretar como metonimia del espacio geográfico latinoamericano según la imagen arquetípica del Caribe.

Parece lógico pues que Katchadjian sitúe los escenarios de la explotación colonial y la emancipación de los sujetos colonizados en espacios utópicos, no reconocibles ni posibles de ubicar a ciencia cierta

${ }^{11}$ Aunque ciertos modismos lingüísticos empleados por los personajes sí conectan la ficción de Katchadjian con la geografía del Cono Sur, no existen mayores trazas en la novela de Katchadjian que la vinculen al contexto político vivido en Argentina en los últimos decenios. A este respecto, Gracias se desmarca notablemente de la llamada por Premat (2017) «literatura de los hijos»», corriente en la que destacan autores como Patricio Pron en Argentina o Alejandro Zambra en Chile, donde se ven representados muchos de los avatares políticos de la historia reciente de los países del Cono Sur. He aquí por lo tanto otro rasgo que afianza la peculiaridad de la obra de Katchadjian, pues siendo como es una novela extremadamente política no deja encasillarse fácilmente dentro de las corrientes reconocibles de la literatura testimonial latinoamericana, si bien no deja de seguir-todo sea dicho- la estela de autores transgresores como Bellatin o Aira. ${ }^{12}$ La imagen inicial de la llegada de los esclavos a la isla es amplificada en el capítulo 5 tal y como sigue: «Llegaban barcos con jaulas pequeñas, de veinte o treinta esclavos, y casi siempre ocurría lo mismo: un empleado del puerto entraba a la jaula, sacaba a los enfermos o desmayados y se los llevaba; después, las ventas se hacían rápidamente; algunas veces, un hombre compraba una jaula entera, y entonces, después de pagarle al empleado, dejaba salir a los cinco esclavos más fuertes y les hacía colocar la jaula sobre una plataforma con ruedas; después, esos cinco esclavos tiraban de la plataforma y la iban desplazando lentamente por un camino verde que se perdía en el monte o por otro camino que debía ir al pueblo» (KATCHADJIAN, 2011, p. 26). 
dentro de una localización geográfica determinada. ${ }^{13}$ Por ello se localiza al protagonista y los personajes que le acompañan en su rebeldía-Nínive, Hugo, etc.- en parajes que recuerdan por momentos a las islas perdidas en medio del océano donde se ambientan clásicos del siglo XVIII como Robinson Crusoe o Gulliver's Travels. Un espacio colonial por excelencia que refleja perfectamente la dominación de un poder imperialista ilimitado e ilocalizable, fruto del «descentramiento» o «pérdida de periferia», y que encarna a la perfección la «periferia mezclada» según la definición - a partir de los postulados de Sloterdijk- de Emanuela Fornari (2017). En definitiva: una colonia imperial sin metrópolis.

Recapitulando, la metrópolis para la crítica poscolonial y antiimperialista que parece encerrar la novela de Katchadjian no se identifica con una nación concreta, sino con una entidad esclavizadora cuyo dominio y cuya explotación se extienden por toda la vasta extensión de la isla insospechada que sirve de escenario para las atrocidades cometidas contra los protagonistas y que fuerzan su rebeldía y liberación contra el poder dominante. ${ }^{14}$ Un espacio ya no euclídeo, siguiendo a Fornari (2017), donde el dominio y la explotación (neo)imperialistas «se extienden para cubrir el planeta entero, poniendo en jaque cualquier tentativa de trazar una cartografía lineal de los modernos dispositivos de poder y de las correlativas prácticas subjetivas de liberación y de "resistencia"».

«Es momento de que empecemos a romper las cadenas de la esclavitud», afirma el protagonista de la novela de Katchadjian (2011, p. 31-32). ${ }^{15}$ Pero resulta inevitable preguntarse: ¿quién ejerce esa esclavitud?

\footnotetext{
${ }^{13}$ Esta imposibilidad de determinar el espacio de la novela dentro de unas coordenadas geográficas concretas y reconocibles se extiende por igual y como es lógico al tratamiento del tiempo en la novela, caracterizado por la yuxtaposición de elementos temporales dispares que acaban por generar un universo anacrónico.

${ }^{14}$ Teniendo presente esta lectura, se podría interpretar por consiguiente que quizás la isla sea una representación metafórica del territorio latinoamericano como espacio colonizado por el dominio imperial -o por extensión si cabe del propio planeta y la sociedad global actual. De forma que los personajes representan por igual una (pos) humanidad esclavizada por el poder anónimo del neoimperialismo capitalista. Asimismo es posible interpretar que los habitantes de la isla son un trasunto del propio pueblo latinoamericano en oposición a los intereses coloniales que han existido desde la llegada de los europeos en el nuevo continente.

${ }^{15}$ Más que significativo resulta, a este respecto, el alegato combativo del protagonista: «Me pareció apropiado decirles algo en ese momento, y les dije lo que me salió: que
} 
¿Qué imperio es el responsable de tales barbaries? En el contexto actual, en un escenario posfordista de la economía, en un estado avanzado del capitalismo, el nuevo imperialismo neocolonial procede de los efectos de la globalización económica, del liberalismo desregularizado, de la explotación de los recursos económicos con que las grandes potencias mundiales, a través de sus multinacionales, han pretendido someter en las últimas décadas la soberanía de las naciones latinoamericanas.

La enseñanza que se desprende de la novela incide en que no hay final para el colonialismo, para la esclavitud, para la barbarie. El imperialismo no muere sino que se transforma y regenera constantemente: por más que se combata y luche, no tiene fin. Si bien el protagonista huye de la isla en un barco que surca el mar abierto del océano, símbolo de la apertura, de la libertad, de la desterritorialización, el imperialismo encontrará tarde o temprano nuevas vías de dominio y explotación. ${ }^{16}$ Nuevas formas de esclavitud más allá de la lucha. No hay fin de la lucha, como no hay fin de la historia de la dialéctica entre dominante y dominado. Únicamente la conversión del imperialismo en un sistema de opresión diferente, merced a la naturaleza proteica del instinto territorial del ser humano: la dominación del hombre como lobo para el hombre.

No sorprende por ello que la novela concluya de forma irónica. ${ }^{17}$ Acontece cuanto en tantísimas ocasiones, por desgracia, ha sucedido

la voz de la libertad estaba en nuestros corazones y que era nuestro objetivo hacerla gritar cada vez más fuerte, y que antes era mejor ser un muerto que un esclavo. Hubo un silencio, y entonces, incómodo, decidí gritar en forma de eslogan lo último que había dicho: “¡Mejor muertos que esclavos!”. Volví a gritarlo, esta vez mirándolo a Hugo para que lo repitiera conmigo. Hugo y yo lo repetimos, y uno o dos esclavos se animaron también. A la quinta vez, ya éramos varios. A la décima, todos lo gritábamos con exaltación: “iMejor muertos que esclavos!”” (KATCHADJIAN, 2011, p. 49).

${ }^{16}$ Recuérdese asimismo la alegoría política que encierra la nave como símbolo en la tradición literaria de Occidente y la significación que podría albergar en el contexto de la novela de Katchadjian.

${ }^{17}$ De hecho, es posible realizar una lectura diferente de la novela de Katchadjian, pues en ocasiones el impulso liberador de los esclavos y el espíritu revolucionario compartido por el protagonista y sus compañeros son puestos en entredicho por resultar improvisados y faltos de verdadero proyecto político: «Le respondí que no sabía, que ya veríamos» (KATCHADJIAN, 2011, p. 49); «No sé cómo va a evolucionar eso» (KATCHADJIAN, 2011, p. 56). Incluso puede llegar a observarse una crítica implícita en la novela de Katchadjian a la ignorancia de los esclavos - «Me di cuenta de que nadie había entendido 
en los procesos de emancipación colonial: «se ha sustituido una élite dominante por otra», cuando no ha dado lugar «la lucha entre diferentes grupos étnicos por la hegemonía y el control de los Estados poscoloniales emergentes [...] a ulteriores divisiones, fragmentaciones y segregaciones, cuando no a verdaderas guerras y masacres» (MELLINO, 2008, p. 103). Así mismo sucede en los últimos compases de Gracias, toda vez que los personajes acaban esclavizados despiadadamente por uno de sus compañeros, Calambra, «que no sólo no había liberado a nadie, sino que se había provisto de nuevos esclavos a los que trataba peor que el peor amo imaginable» (KATCHADJIAN, 2011, p. 112).

Esta naturaleza proteica del Imperio, esta «lógica del exceso integrado» del propio capitalismo (FORNARI, 2017), puede señalarse como referente de la podredumbre infinita que acaba por invadirlo y contaminarlo todo al término de la novela; esa misma podredumbre de la que el protagonista ha tratado de deshacerse para siempre en los galpones según el mandato de Aníbal, pero que acaba por extenderse en forma de cenizas y gusanos por toda la isla hasta que no queda otra opción que desalojarla y evacuar a los esclavos.

En la misma línea, puede interpretarse que los excesos del capitalismo encuentran reflejo en los propios excesos violentos de la novela. De la misma forma que el imperialismo domina la vasta extensión de la isla, la violencia se desatará con mayor furor contra los opresores. Todo ello alimenta la podredumbre que, como metáfora de la barbarie colonial, no se detiene ante nada ni ante nadie. Es imparable como imparable es el imperialismo. Acaba por infestar de cenizas y gusanos

nada» (KATCHADJIAN, 2011, p. 57)- y su incapacidad para asimilar su identidad al margen de la propia esclavitud y su nueva función como soldados de la revolución, pues acabarían convirtiendo «esa función en una identidad, y entonces querrían seguir peleando aun cuando el enemigo se hubiera extinguido» (KATCHADJIAN, 2011, p. 56). No obstante, Nínive se encarga de recordarle al protagonista que el enemigo nunca se extingue y no hay forma realmente de poner fin al combate, al dominio y con él a las nuevas formas de tiranía y esclavitud, algo que se evidencia con los actos de barbarie cometidos por Calambra al final de la novela. Lo cierto es que en Gracias convergen dos visiones filosóficas enfrentadas: el idealismo del protagonista, que interpreta que sólo es posible alcanzar la libertad efectiva en el momento en que se es consciente de «la diferencia entre esclavitud y libertad» (KATCHADJIAN, 2011, p. 57), frente al pragmatismo de Hugo, quien defiende que «quizá la conciencia llegue después de la libertad efectiva» (KATCHADJIAN, 2011, p. 58). 
el territorio insular como un virus descontrolado, fruto del exceso del que se nutre el poder del capital y los imperios.

Esta es la causa que parece inspirar la novela reivindicativa de Katchadjian. Tomando como referente la esclavitud colonial, puede que el objetivo no sea otro que la representación de las «vidas desperdiciadas», valiéndonos del concepto acuñado por Zygmunt Bauman (2005), las cuales no tienen cabida en el proceso de globalización «a no ser bajo el signo de una disciplina carcelaria y premoderna del trabajo, en los circuitos de la producción y de la acumulación» (FORNARI, 2017). Pero lo cierto es que ya no se identifica la tiranía (neo)imperial con un agente colonial metropolitano, sino que encarna el sistema capitalista en su dimensión global el nuevo monstruo de la barbarie colonizadora. Un imperialismo que no reconoce jamás la dignidad del ser humano, que no respeta el contrato social y fomenta la ruptura de las normas que rigen el parque humano.

Cobra aquí sentido nuevamente la tesis combativa de Fanon (1988) vislumbrada en el comportamiento violento de los personajes de Katchadjian: «El campesinado, el desclasado, el hambriento, es el explotado que descubre más pronto que sólo vale la violencia» (FANON, 1988, p. 47). No es descabellada, por políticamente incorrecta que resulte, la resolución del conflicto que encierra la alegoría poscolonial presente en Gracias: la resistencia violenta y el uso de la fuerza son las únicas respuestas posibles al proceso inhumano de explotación y esclavitud. La muerte de Aníbal es un acto de barbarie que pone fin a la barbarie. Pero sólo temporalmente, pues como denuncia Katchadjian (2011, p. 56) a través de la esclava Nínive, expresando el credo de la teoría poscolonial, «el enemigo nunca se extingue».

\section{Referencias}

APPADURAI, A. La modernidad desbordada: dimensiones culturales de la globalización. Montevideo: Trilce, 2001.

BALIBAR, E. Prefacio. In: FORNARI, E. Líneas de frontera: filosofía y postcolonialismo. Barcelona: Gedisa, 2017. E-book. No paginado.

BAUMAN, Z. Vidas desperdiciadas: la modernidad y sus parias. Buenos Aires: Paidós Ibérica, 2005. 
BECK, U. ¿Qué es la globalización?: Falacias del globalismo, respuestas a la globalización. Barcelona: Paidós, 1998.

FANON, F. Los condenados de la tierra. México D.F.: Fondo de Cultura Económica, 1988.

FERNÁNDEZ MALLO, A. Trilogía de la guerra. Barcelona: Seix Barral, 2018.

FERRÉ, J. F. Providence. Barcelona: Anagrama, 2009.

FORNARI, E. Lineas de frontera: filosofía y postcolonialismo. Barcelona: Gedisa, 2017. E-book. No paginado.

GRÜNER, E. El fin de las pequeñas historias: de los estudios culturales al retorno (imposible) de lo trágico. Buenos Aires: Paidós, 2002.

HALL, S. When Was the Post-Colonial? Thinking at the Limit. In: CHAMBERS, I.; CURTI, L. (Ed.). The Post-Colonial Question: Common Skies, Divided Horizons. Londres: Routledge, 1996. p. 242-260.

KATCHADJIAN, P. Gracias. Buenos Aires: Blatt \& Ríos, 2011.

MELLINO, M. La crítica poscolonial: descolonización, capitalismo y cosmopolitismo en los estudios poscoloniales. Buenos Aires: Paidós, 2008.

MIGNOLO, W. Historias locales / diseños globales: colonialidad, conocimientos subalternos y pensamiento fronterizo. Madrid: Akal, 2003.

PREMAT, J. Yo tendré mis árboles: los comienzos en Zambra. Taller de Letras, Santiago de Chile, n. 60, p. 87-105, 2017.

REPILA, I. Prólogo para una guerra. Barcelona: Seix Barral, 2017.

SASSEN, S. Una sociología de la globalización. Buenos Aires: Katz Editores, 2007.

ŽIŽEK, S. Multiculturalismo o la lógica cultural del capitalismo multinacional. In: JAMESON, F.; ŽIŽEK, S. Estudios culturales: reflexiones sobre el multiculturalismo. Barcelona: Paidós, 1998. p. 137-188.

Recebido em: 9 de julho de 2018. Aprovado em: 2 de novembro de 2018. 